\title{
Meteorological Drought in Northwestern Escarpment of Ethiopian Rift Valley: detection seasonal and spatial trends
}

\author{
Jemal Nasir ${ }^{1,2^{*}} \mathbb{C}$, Engdawork Assefa ${ }^{1}$, Tesfaye Zeleke ${ }^{1}$ and Eskinder Gidey ${ }^{3}$
}

\begin{abstract}
Background: The Northwestern Escarpment of the Ethiopian Rift Valley has been frequently affected by droughts for decades. The area is among the most drought-prone and chronically food-insecure parts of the country. The study areas that include the Raya Valley livelihood Zone (RVLZ), Alagie-Offla livelihood Zone (ALOFLZ), and Tsirare Catchment Livelihood Zones (TCLZ) are amongst the most vulnerable and badly affected livelihood zones in the Northwestern Escarpment of the Ethiopian Rift Valley. Hence, this study aimed to monitor the meteorological drought conditions of the three LZs from 1983 to 2016 using the Standardized Precipitation Evapotranspiration Index (SPEI) at three months' time scale. Both monthly Climate Hazards Group InfraRed Precipitations with Station data (CHIRPS) and Enhancing National Climate Service (ENACTS) temperature data (1983-2016) at moderate spatial resolution (i.e. 4 km-by-4 km) were obtained from the National Meteorological Agency of Ethiopia.

Results: This study uncovers seasonally recurring droughts that vary in severity, frequencies, and durations within and between the livelihood zones. The results indicated that severe drought occurred in all livelihoods zone of the study area from years 1983 to 1991, while ALOFLZ and TCLZ have recorded relatively higher drought severity. From 1989 to 2016, the severity and frequency of droughts were increased during the Belg (small rain) season but decreased in Kiremt (summer). In most of the study years, there have been Belg or Kiremt or both drought seasons in the study areas. The severity and frequencies of Kiremt drought in this study were higher from 1983 to 1991, better 1993-1998, and mildly to moderate drought from 2000 to 2016. As the frequencies and persistence of mild drought have increased, the intensity and precipitation amount are too small to cultivate crops and forage growth. This problem needs special considerations on the current moisture harvesting system and afforestation practices to reduce natural and human-induced drought impacts.

Conclusions: Studying drought with long recorded meteorological data from a large number and uniformly distributed meteorological grids in small scale livelihood zones had great implications to identify the real trends of spatiotemporal meteorological drought. This enabled the researchers to investigate the real drought frequencies, severity, and durations in small scale areas. The study will support to improve the existing drought monitoring system and to build resilience to drought at the household level. The finding also will have a significant contribution to early warning systems, particularly at district levels. Ended, it needs to consider solutions for short and long drought impacts. The agricultural sector should consider the long-cycle crop growth patterns to reduce crop failures and forage problems.
\end{abstract}

\footnotetext{
*Correspondence: yasanasir@gmail.com

${ }^{1}$ Center for Environmental and Development Studies, College

of Development Study, Addis Ababa-University, P. O. Box: 1176, Addis

Ababa, Ethiopia

Full list of author information is available at the end of the article
}

Springer Open

(c) The Author(s) 2021. This article is licensed under a Creative Commons Attribution 4.0 International License, which permits use, sharing, adaptation, distribution and reproduction in any medium or format, as long as you give appropriate credit to the original author(s) and the source, provide a link to the Creative Commons licence, and indicate if changes were made. The images or other third party material in this article are included in the article's Creative Commons licence, unless indicated otherwise in a credit line to the material. If material is not included in the article's Creative Commons licence and your intended use is not permitted by statutory regulation or exceeds the permitted use, you will need to obtain permission directly from the copyright holder. To view a copy of this licence, visit http://creativeco mmons.org/licenses/by/4.0/. 
Keywords: Belg, Kiremt, Livelihood zones, Meteorological Drought, Northwestern Escarpment of the ethiopian Rift Valley, SPEI

\section{Background}

Drought is a recurrent natural phenomenon that occurs in most parts of the globe, even in the wet and humid regions (Dai 2011; He et al. 2011; Masih et al. 2014; Tian 2019; Zarei 2019). It is one of the natural disasters that extensively damage the environment and the economy in several ways (e.g., agriculture, water resources, ecologies, human welfare, and animal life) (Mavromatis 2012; Lu et al. 2015; Tefera and Bello 2019; Chen et al. 2020; Yacoub and Tayfur 2020). According to the Emergency Events Database (EM-DAT 2014), approximately 642 drought events were reported across the globe in the period 1900-2013. These events claimed the lives of 12 million people and affected over 2 billion people. The total economic damages were also estimated at nearly 135 billion USD. Masih et al. (2014) reported that there were about 291 drought events that affected more than $362,225,799$ people during the period $1900-2013$ in Africa. In Ethiopia, drought is a common occurrence and it has been, and still is, the main driving cause behind the country's exposure to periodic famine (Webb and Braum 1990; Kiros 1991; Andargie 2014). According to EM-DAT (2017), the degree of drought varies in intensity, spatial and temporal coverage in Ethiopia. From 1973 to 2016, about 26 mild-severe droughts have occurred in northern Ethiopia (Gebru and Beyene 2012; EM-DAT 2017), which overlays with the territories of the current study settings. Since 1965 the country has been revisited with drought events at regular occurrences within ten-year intervals (Andargie 2014). However, in recent years (since 2000), drought has been occurring within 2-3 years' time intervals (Gidey 2012; Gidey et al. 2018a, b).

As a land of multiple paradoxes, in Ethiopia, the rural settings have been divided into pastoral, agro-pastoral, and cropping livelihood zones. These three broad livelihood zones in turn sub-split into 175 livelihood zones based on economic geography (The Livelihoods Integration Unit 2010). The three livelihood zones of the study areas include the Raya Valley livelihood Zone (RVLZ), Alagie-Offla livelihood Zone (ALOFLZ), and Tsirare Catchment Livelihood Zones (TCLZ) are among these livelihood zones. These three major livelihood zones (LZs) are among the most droughts prone and chronically food-insecure areas of the country (Andargie 2014). Agriculture and livestock, which comprise the main livelihood system in the three LZs are frequently affected by drought. This costs thousands of human lives and brought an adverse effect on the social and economic sectors because it affects significantly the smallholder farmers of the area (Abrha and Simhadri 2015; Tefera and Bello 2019). According to Gebru and Beyene (2012), the chronic nature of food insecurity leads to not only deprivation of access to immediate food demands, but also to the depletion of assets, which are expended and distresssold for procuring food from the market or other sources.

Ethiopia had adopted the National Disaster Risk Management Policy and Strategy in 2013 to reduce disaster risks and potentials damages caused by disasters (Drechsler and Soer 2016). However, the Woreda Disaster Risk Profiles (WDRPs) have not been executed at the local level Biru and Amanuel M. Dibaba (2018). Many authors such as Kenawy et al. (2016) over Ethiopia, Mohammed (2018) in North East Highland of Ethiopia, and Gidey (2012) in Tigray Regional State corroborated the presence of locally embedded characters of drought evolution, that needs detail spatial drought studies to provide evidence for policymakers to adopt appropriate local polices to cope up with the risks of drought. Since 2000 , drought has become almost a normal phenomenon and most of the year, apart from the rainy seasons, the area is dominated by dry weather and revisited with severe droughts (Gidey 2012; Gidey et al. 2018a, b, c; Tefera and Bello 2019). In the three LZs, the agro-ecosystem is very sensitive to precipitation change. The changes or variability in precipitation amount and distribution have negative impacts on the environment as well as on the livelihood of marginal households. In most cases, drought recurs before the affected area has recovered from the most recent drought event (Abrha and Simhadri 2015).

Several studies related to drought have been conducted using SPEI in different parts of the globe. For instance, Abbasi et al. (2019) studied drought using SPEI and gene expiration model from 1951 to 2009 for all time scales in Urmia, Iran. They found that the prediction accuracy was increased by increasing SPEI time scales, and it is better than indicators that only use precipitation data and it also can be an indicator of hydrological drought. Bae et al. (2018), found out the characteristics of drought based on SPEI using Thornthwaite and Penman-Monteith equations in South Korea from the year 1981-2010. They found that SPEI using Penman-Monteith equations slightly shows severe drought than Thorn Thwaite equations. Diaz et al. (2020), study drought tracks using gird data from SPEI in India from 1901 to 2013, and 
they found the severity, duration, onset, and end positions track of the drought. Beharry et al. (2019) studied to build baseline scenarios of meteorological droughts using SPI Index for the southernmost Caribbean islands of Trinidad and Tobago from 1980 to 2014. Their result shows that there are variations of drought characteristics over a small island and the possible adverse effects on surface water reservoirs.

Similarly, few studies have been conducted in Tigray at regional and zonal scale, but not at livelihood zone levels. For instance, Gidey (2012) and Gidey et al. (2018a, b) studied the effectiveness of food security policy in ensuring rural food security and poverty reduction in the Tigray region and assessment of the various drought conditions of the area. Annys et al. (2016) studied the relationship between rainfall variability and land cover changes as impacted by spatial-temporal rainfall variability along the Ethiopian Rift Valley escarpment. Gidey et al. (2018a, b, c, d also analyzed the meteorological, and agricultural droughts onset, cessation, duration, frequency, and spatial extent using an advanced approach of geospatial technologies. Moreover, Abrha and Simhadri (2015) conducted a study on climate change and farmers' perception, and factors affecting the perception of climate change in Southern Tigray. Tefera and Bello (2019) also studied the correlation between SPI and SPEI index for drought measurement in Tigray. These authors have used 12 grids for meteorological data analysis throughout the region.

Most of these reviewed studies have limitations to show the evolutions, spatiotemporal drought frequencies, durations, and severities in livelihood zone levels. The study of drought conditions in zonal, regional, national, or continental levels could generalize the situations of the vulnerable areas which need special focuses and local solutions based on the magnitude of their vulnerabilities. So far, there has been little or no intensive study that attempts to capture the frequencies, severity, duration, and spatial coverage of drought at the LZ level which will be data sources for the WDRPs. Most of the reviewed literature indicates that meteorological data were collected from a few stations which were not proportional to their spatiality. But, according to Sadat et al. (2020) drought protection and preparedness depend on longterm recorded and spatially well-distributed meteorological data. Unrepresentative data could not demonstrate a full picture of results that vividly put the magnitude and intensities of droughts as well as the real spatial distributions and time series of these occurrences.

The long and short rainy seasons in the study area are Kiremt (June to August or September) and Belg (March-May) respectively. Rain feed agricultural activities and productivities of the study area depends on the two seasonal precipitations. Also, the Belg and Kiremt seasons are the main moisture sources for animal forage productions as well as sources of moisture budget for the local ecosystems' stabilities of the area. Therefore, to design the right strategies that help to reduce the impacts of drought and to sustain the livelihood of the local communities and their environment, it needs detailed studies of the Belg and Kiremt drought evolution, its tracks, and magnitudes at specified livelihood zones with intensive meteorological data. Hence, this study attempts to detect meteorological drought incidence using SPEI in the Northwestern Escarpment of the Ethiopian Rift Valley. Studying the trends of spatiotemporal drought frequencies, durations, and severities at livelihood zones are important to show the real drought vulnerable area on local levels, which will be used as an input for policies and strategies in drought management and preparedness. Moreover, the outlook of the local drought occurrences in the historic context could facilitate in applying lowrisk and long-term plans to develop strong livelihood systems that can withstand the impacts and strengthen the resilience of communities and to conserve and sustainably use their natural resources. Therefore, this study will support to improve the existing drought monitoring system and to build resilience to drought at the household level. The finding also will have a significant contribution to early warning systems, particularly at district levels in the study area as well as scientific communities that will benefit from the study.

\section{Materials and methods \\ Study area}

This study was conducted in the three livelihood zones of the northwestern escarpment of the Ethiopian rift valley (Raya valley and its adjacent). It is located between $12^{\circ} 20^{\prime} 0^{\prime \prime}$ and $12^{\circ} 50^{\prime} 0^{\prime \prime} \mathrm{N}$ latitude and $39^{\circ} 10^{\prime} 0^{\prime \prime}-$ $39^{\circ} 53^{\prime} 41.7^{\prime \prime} \mathrm{E}$ longitudes in northeastern Ethiopia. The topography of the area includes mountains, plateaus, valleys, and gorges. The area has mainly semi-arid and sub-humid climates characteristics and comprises Dry Kola (500-1500 m.a.s.l), Dry Woinadega (1500-2300 m.a.s.l), Dry Dega (2300-3200 m.a.s.l) and High Dega (wurch) (above 3200 m.a.s.l) agro-climatic zones (Hurni and Zeleke 2018). The study area covers $3809 \mathrm{KM}^{2}$. The RVLZ has Dry Woinadega and Dry Kola agro-climatic zones with an area of 1447 and $386 \mathrm{~km}^{2}$, respectively. The ALOFLZ has Dry Dega and High Dega agro-climatic zones with total area of 1035 and $52 \mathrm{~km}^{2}$, respectively. But TCLZ has only a Dry Woinadega agro-climatic zone with a $933.56 \mathrm{~km}^{2}$ area. The rainfall distribution of the study area is bimodal with abundant rainfall in July and August, and the second smaller rainy season from March to May. The study area receives annual precipitation 
of $400-700 \mathrm{~mm}$ in the semi-arid, while the sub-humid parts of the area receive between 700 and $1000 \mathrm{~mm}$. The maximum average annual temperature ranged between 25.4 and $27.5{ }^{\circ} \mathrm{C}$, while the minimum average annual temperature is between 12.5 and $14.5{ }^{\circ} \mathrm{C}$. Furthermore, the smallholder farmers of the study area practiced a mixed agricultural production system (i.e., crop production and livestock rearing) (Abrha and Simhadri 2015). Besides, sorghum, maize, wheat, barley, pulses, and teff are the predominant crop types grown in the kola and dry-woinadega agro-ecological zones both during the Kiremt (main rain) and Belg (small rain) seasons. Hurni and Zeleke (2018) also reported that barley, wheat, legumes, teff, and pulses are grown in the dry-dega parts of the study area, and the High Dega (wurch) areas are cultivated barley and sometimes potatoes (Fig. 1).

\section{Data collection}

In this study, both the monthly Climate Hazards Group InfraRed Precipitation with Station data (CHIRPS) and Enhancing National Climate Service (ENACTS) Maximum (Tmax) and minimum (Tmin) temperatures data (1983-2016) at moderate spatial resolution (i.e., $4 \mathrm{~km}-\mathrm{by}-4 \mathrm{~km}$ ) have been acquired from the National Meteorological Agency of Ethiopia. Also, CHIRPS-based precipitation data with high resolution $\left(0.05^{\circ}\right)$ were used by (Ghozat et al. 2020) to compare the accuracy of the satellite products with ground-based meteorological stations on daily, monthly, and annual scales in Iran. Here in this study the collected CHIRPS and ENACTS data were free of zero missing values and used to compute drought frequency, duration, magnitude, and spatial coverage.

\section{Data processing, analysis, and interpretation}

The Standardized Precipitation Evapotranspiration Index (SPEI) which is one of the prominent meteorological drought indices was applied to analyze the condition of drought incidence at three months time scale in the study area. SPEI has been widely used for drought measurements and water balance estimation across the globe (Shi et al. 2017). Vicente-Serrano et al. (2012) reported that the index combined Palmer Drought Severity Index (PDSI) to simplify the detection of meteorological drought incidence. For the calculation of the SPEI, the first step is to find the probability density function using the gamma probability density function which best describes the distribution of the precipitation data over different time scales using the same computing procedure of the SPI (Zhang and Shen 2019). However, the inputs required to calculate SPEI program are precipitation and Potential Evapotranspiration (PET). World Meteorological Organizations (WMO) recommends using the Penman-Monteith (MP) equation to calculate PET.

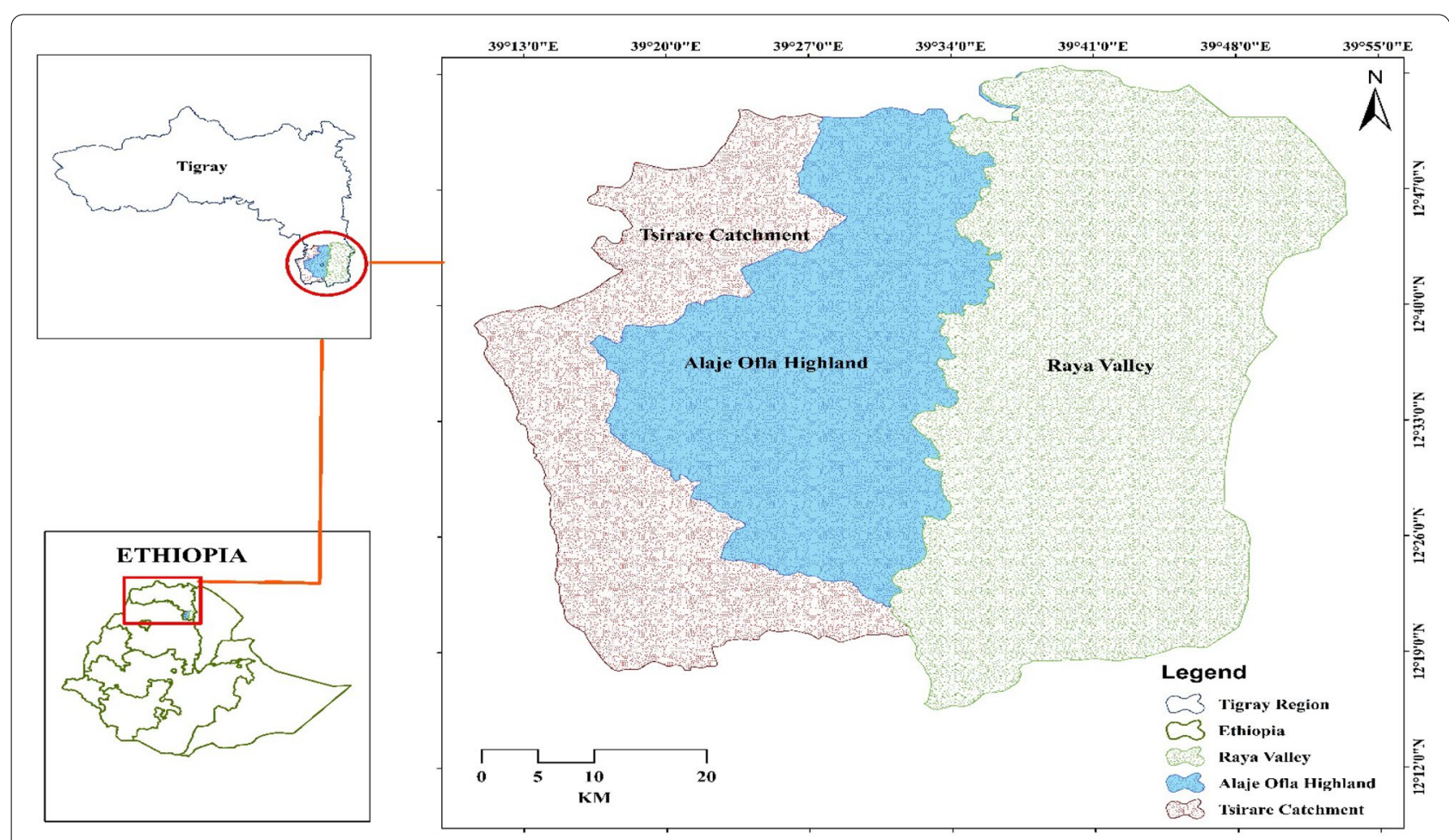

Fig. 1 The location of the study area (Source: FEWS NET 2018) 
However, Penman-Monteith (MP) equation requires long recording data of solar radiation, temperatures, wind speed, and relative humidity which are not easily available in meteorological stations in routinely measuring and long-term records particularly in developing countries Bae et al. (2018). Therefore, if there is a limitation of data, Beguería et al. (2014), are recommended Hargreaves $(\mathrm{Hg})$ equations as the first and Thornthwaite (Th) equations as the second alternatives to estimate PET to calculate SPEI using R packages. So that, to run the PET of this study, depending on the availability of the maximum and minimum temperatures, precipitations, longitude, and latitudes data, the Hargreaves $(\mathrm{Hg})$ equation was used.

$$
S P E I=P-P E T
$$

where $P$ monthly average rainfall and $P E T$ is monthly Potential Evapotranspiration. For further information on the SPEI tool visit http://sac.csic.es/spei/index.html (Table 1).

After analysis, the magnitude and severity of the drought within the SPEI index the spatial and temporal trends of the drought were further analyzed and mapped in ArcGIS. The Inverse Weighting Methods (IDM) method was used to interpolate the spatial drought trends. The IDM is an important tool for rainfall distributions and drought occurrences interpolation in heterogamous geographies (Mohammed 2018). Since the meteorological data were collected proximately $4 \mathrm{~km}$ by $4 \mathrm{~km}$, Thiessen polygon was applied to calculate accurate areas of each gird's points. Using each gird area, the spatial drought coverages were computed for the studying drought seasons of the study livelihood zones. The GraphPad Prism version 8.4.2 was used to see and to compare the drought spatial extension trends between the three LZs using simple linear regression.

\begin{tabular}{ll}
$\begin{array}{l}\text { Table } 1 \text { Meteorological } \\
\text { or interpretation by SPEI (Sources: Mckee et al. 1993) }\end{array}$ & $\begin{array}{c}\text { drought } \\
\text { classification }\end{array}$ \\
\hline Descriptions & \multicolumn{1}{c}{ SPEI values } \\
\hline Very wet & 1.5 to 1.99 \\
Moderately wet & 1.00 to 1.49 \\
Mildly wet & 0 to 0.99 \\
Mild drought & 0 to -0.99 \\
Moderate drought & -1.0 to -1.49 \\
Severe drought & -1.5 to -1.99 \\
Extreme drought & $<-2$ \\
\hline
\end{tabular}

\section{Results and discussions}

Results

\section{Drought characteristic in the study area}

Studying the spatiotemporal trends of drought is important to carry out the analysis of the impacts of drought. The long and short rainy seasons in the study area are Kiremt (June to August or September) and Belg (March to May) respectively. Both seasons are the main rain sources to cultivate short as well as long cycle growth crops. Rain feed agricultural activities and productivities of the study area depends on the two seasonal precipitations. Also, the Belg and Kiremt seasons are the main moisture sources for animal forage productions as well as sources of moisture budget for the local ecosystems' stabilities of the area. Small precipitation change in one or both seasons can have consequences of crop failure and forage problems in the study area. Shortage of precipitations for continuous months particularly during the consecutive rainy seasons has great impacts on rain feed agriculture systems. If there is a period of months to years of prolonged dry weather conditions due to precipitation departure in a certain region, meteorological drought may occur and these may have high impacts on water resources, agricultural activities, meteorological cycles, ecosystem processes, and social affairs (Sharafati et al. 2019). Consequently, the focus of this spatiotemporal drought study was emphasized on short (the Belg and Kiremt), combined (March-August) rainy season drought trends.

For the temporal drought trend results, charts, and figures were presented and for the spatial drought trends, the researcher preferred to put tables, graphs, and maps for each LZs. Summary of spatial coverage for SPEI value for Belg and Kiremt seasons for the measured time scales from 1983 to 2016 were presented in Tables 2 and 3, respectively. The colors of the maps below in Fig. 3 for the Belg season and Fig. 7 for the Kiremt season indicated the magnitude of the drought or wet seasons in SPEI3. The red and green colors represented the drought and wet season respectively. The blue color in the red and green maps presented for the highest or the lowest SPEI value for the drought and wet seasons respectively. But since the colors presented to show the range of SPEI3 magnitude at a gird level, the red or the green colors does not mean $100 \%$ drought or wet season; rather they indicated the extent of spatial drought or wet season coverage in the livelihood zones. Since the SPEI values were stated in ranges using IDW it was influenced with neighborhood grid points SPEI3 values. For the detail of the highest and lowest value of SPEI3 in each map see Fig. 3 for Belg and Fig. 7 for Kiremt. The area coverages of drought magnitude for the scales for each year's see below in Table 2 for Belg and in Table 3 for the Kiremt seasons. 
Table 2 Spatial drought trends in \% of area coverage $n$ Belg season from 1983-2016

\begin{tabular}{|c|c|c|c|c|c|c|c|c|c|c|c|c|c|c|c|}
\hline \multirow[t]{3}{*}{ Years } & \multicolumn{15}{|c|}{ Spatial drought area coverage in \% for Belg season } \\
\hline & \multicolumn{5}{|c|}{ ALOFLZ $\left(1106.19 \mathrm{~km}^{2}\right)$ in $\%$} & \multicolumn{5}{|c|}{$\operatorname{TCLZ}\left(933.56 \mathrm{~km}^{2}\right)$ in $\%$} & \multicolumn{5}{|c|}{ RVLZ $\left(1850.10 \mathrm{~km}^{2}\right)$ in \% } \\
\hline & DF & MD & MOD & SD & ESD & DF & MD & MOD & SD & ESD & DF & MD & MOD & SD & ESD \\
\hline 1983 & 72.05 & 27.95 & - & - & - & 54.26 & 45.74 & - & - & - & 98.04 & 1.96 & - & - & - \\
\hline 1984 & - & 81.45 & 9.16 & - & - & 10.72 & 74.61 & 14.66 & - & - & 11.97 & 75.31 & 9.95 & 2.77 & - \\
\hline 1985 & 93.98 & 6.02 & - & - & - & 100 & - & - & - & - & 100 & - & - & - & - \\
\hline 1986 & 100 & - & - & - & - & 100 & - & - & - & - & 100 & - & - & - & - \\
\hline 1987 & 100 & - & - & - & - & 100 & - & - & - & - & 100 & - & - & - & - \\
\hline 1988 & - & 100 & - & - & - & - & 100 & - & - & - & 14.05 & 85.95 & - & - & - \\
\hline 1989 & 100 & - & - & - & - & 97.38 & 2.62 & - & - & - & 99.06 & 0.94 & - & - & - \\
\hline 1990 & - & 10.73 & 89.27 & - & - & - & 61.98 & 38.02 & - & - & - & 55.57 & 44.43 & - & - \\
\hline 1991 & - & 6.27 & 54.58 & 1.57 & 17.32 & - & 49.92 & 42.66 & 7.42 & - & - & 11.44 & 84.82 & 3.75 & - \\
\hline 1992 & 93.73 & 6.27 & - & - & - & 100 & - & - & - & - & 100 & - & - & - & - \\
\hline 1993 & 100 & - & - & - & - & 100 & - & - & - & - & 100 & - & - & - & - \\
\hline 1994 & - & 75.18 & 24.82 & - & - & 30.17 & 69.83 & - & - & - & 36.00 & 64.00 & - & - & - \\
\hline 1995 & 100 & - & - & - & - & 100 & - & - & - & - & 100 & - & - & - & - \\
\hline 1996 & 100 & - & - & - & - & 100 & - & - & - & - & 100 & - & - & - & - \\
\hline 1997 & 100 & - & - & - & - & 100 & - & - & - & - & 100 & - & - & - & - \\
\hline 1998 & 1.57 & 98.43 & - & - & - & 9.34 & 90.66 & - & - & - & - & 100 & - & - & - \\
\hline 1999 & - & 1.57 & 28.19 & - & - & 100 & - & - & - & - & - & - & - & 42.4 & 57.62 \\
\hline 2000 & - & 100 & - & - & - & 4.47 & 95.53 & - & - & - & - & 100 & - & - & - \\
\hline 2001 & 46.99 & 53.01 & - & - & - & - & 45.23 & 14.96 & 39.80 & - & 3.17 & 86.80 & 10.02 & - & - \\
\hline 2002 & 36.03 & 54.80 & 6.03 & - & - & 24.89 & 30.38 & 28.22 & 16.50 & - & 10.47 & 87.93 & 1.60 & - & - \\
\hline 2003 & 68.92 & 31.08 & - & - & - & 26.82 & 70.56 & 2.62 & - & - & 48.94 & 51.06 & - & - & - \\
\hline 2004 & - & 43.61 & 56.39 & - & - & - & 32.44 & 67.56 & - & - & - & 94.02 & 5.98 & - & - \\
\hline 2005 & 100 & - & - & - & - & 100 & - & - & - & - & 50.25 & 49.75 & - & - & - \\
\hline 2006 & 100 & - & - & - & - & 100 & - & - & - & - & 99.06 & 0.94 & - & - & - \\
\hline 2007 & - & 100 & - & - & - & - & 100 & - & - & - & - & 90.45 & 9.55 & - & - \\
\hline 2008 & - & 36.01 & 48.33 & - & - & 7.95 & 49.24 & 42.81 & - & - & - & 3.55 & 56.20 & 40.3 & - \\
\hline 2009 & - & 37.59 & 46.76 & - & - & - & 18.09 & 80.07 & 1.84 & - & - & 9.17 & 84.18 & 6.65 & - \\
\hline 2010 & 62.41 & 37.59 & - & - & - & 91.96 & 8.04 & - & - & - & 94.26 & 5.74 & - & - & - \\
\hline 2011 & 100 & - & - & - & - & 100 & - & - & - & - & 100 & - & - & - & - \\
\hline 2012 & 28.19 & 71.81 & - & - & - & 55.03 & 44.97 & - & - & - & 6.64 & 93.36 & - & - & - \\
\hline 2013 & - & 20.35 & 21.93 & 3.13 & 34.65 & - & 7.91 & 16.27 & 58.65 & 17.2 & - & 31.51 & 61.20 & 7.30 & - \\
\hline 2014 & 14.10 & 76.50 & 9.40 & - & - & - & 100 & - & - & - & - & 96.83 & 3.17 & - & - \\
\hline 2015 & 56.14 & 43.86 & - & - & - & 56.93 & 43.07 & - & - & - & 38.12 & 54.50 & 7.38 & - & - \\
\hline 2016 & 96.87 & 1.57 & - & 1.57 & 17.33 & 59.65 & 28.47 & 2.24 & 9.64 & - & 46.61 & 52.45 & 0.94 & - & - \\
\hline
\end{tabular}

DFDrought Free, MD Mild Drought, MODModerate Drought, SDSevere Drought, ESD Extremely Severe Drought, (-) Zero value

\section{Drought condition during the Belg season}

From 1983 to 2016 in Belg 18 mild, moderate, and severe seasonal temporal droughts were recorded. From theses seasonal drought years, 1990, 1991, 1999, 2000, 2003, 2004, 2008, 2009, and 2013 were recorded from moderate to severe seasonal droughts in SPEI3. The frequencies of seasonal drought for Belg had increased since 1998 in all livelihood zones. The SPEI3 temporal drought trends are indicated in Fig. 2. As seen in the chart, the longest persistent drought years for this season were occurred for seven years from 1998 to 2004 and followed by five drought seasons from 2012 to 2016. From 1983 to 1999 there were high severity and short frequencies of Belg drought. Within the past 34 years (1983-2016), 1999 was recorded as the severe temporal Belg drought in SPEI3 in all livelihood zones. The magnitude was ranged from -1.71 in TCLZ to -1.88 SPEI values in RVLZ.

From 1983 to 1999 , there were ten moderate up to severity wet Belg seasons in all livelihood zones but, with slight differences with the livelihood zones and the 


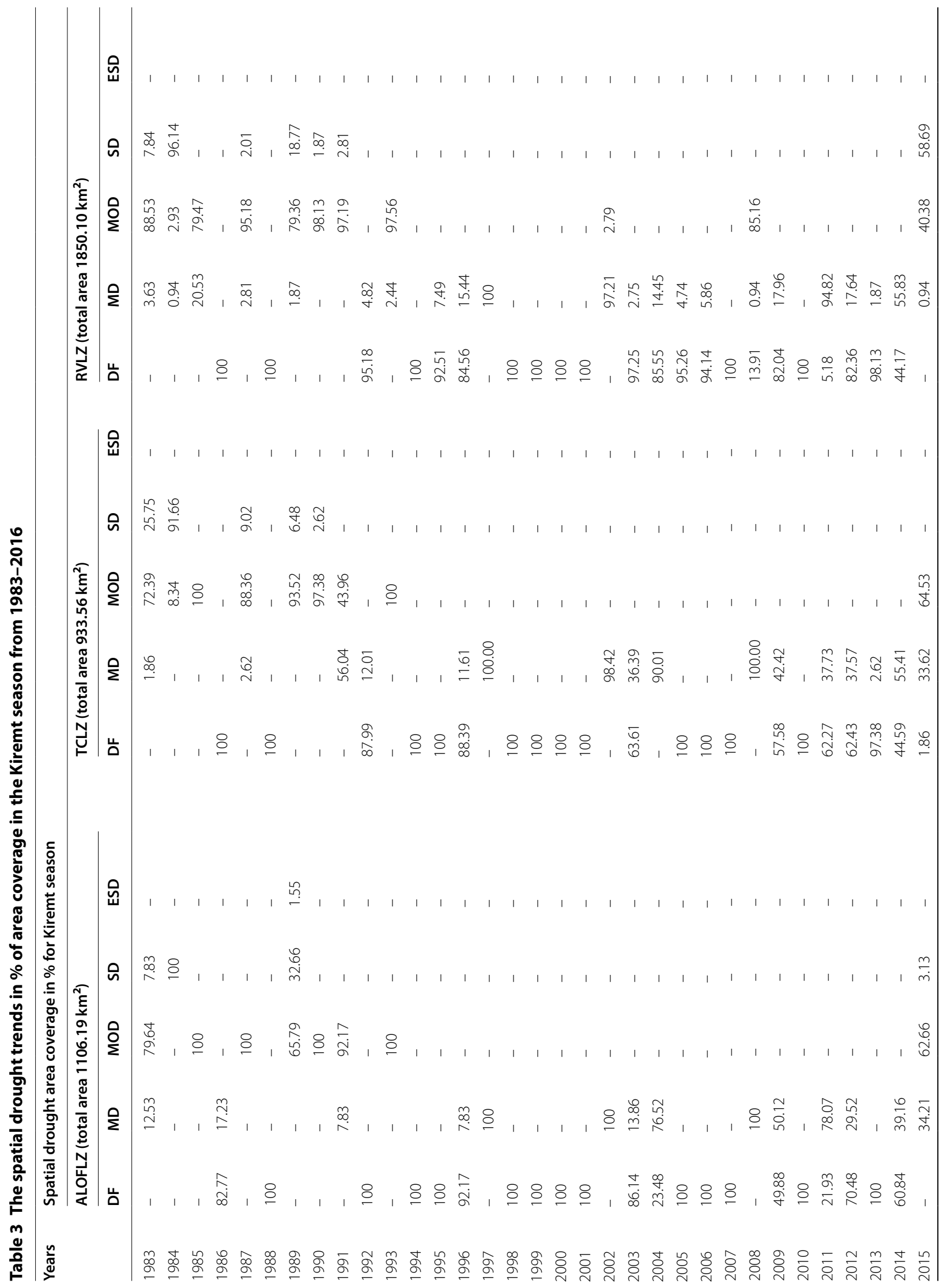




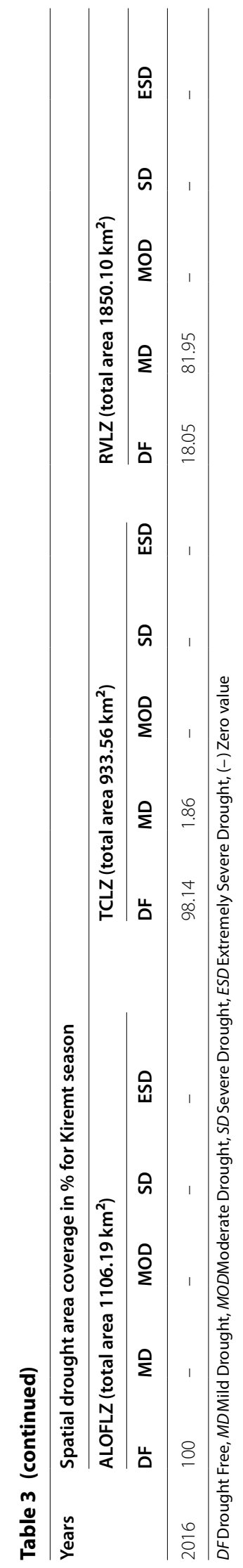




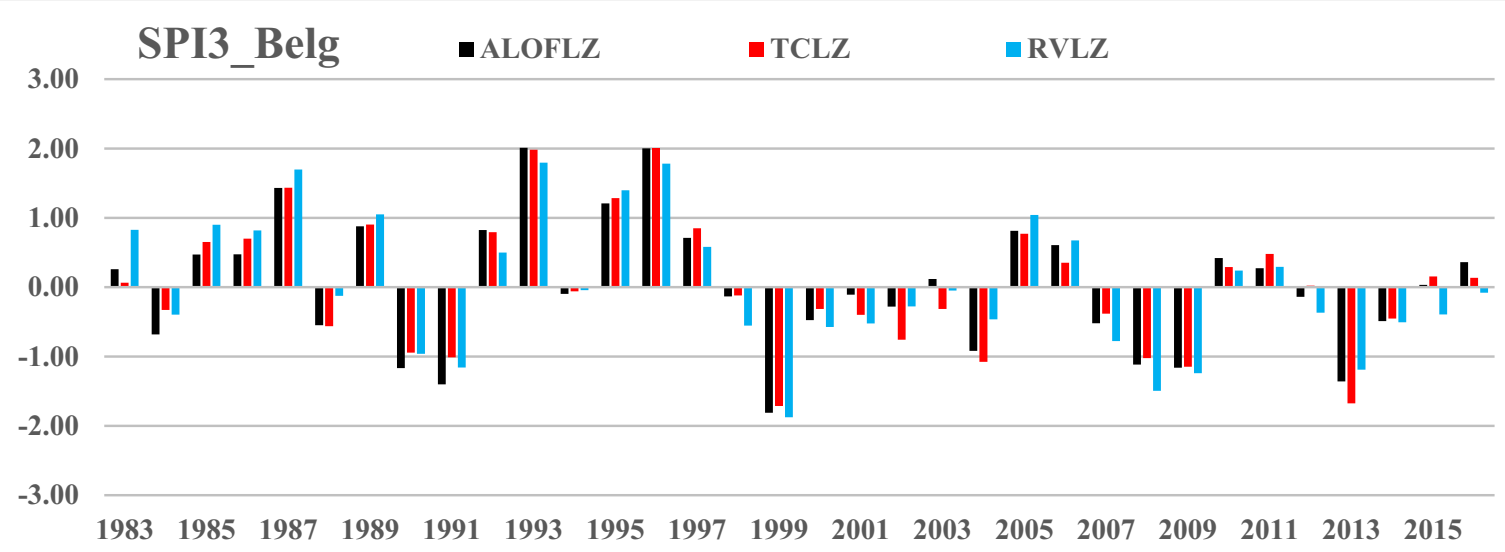

Fig. 2 Temporal drought trends in Belg seasons from 1983-2016

indexes. From the years 2000-2016, there were four wet Belg seasons in all livelihood zones and both indexes. The years of 1994 and 1997 were recorded as the highest wet Belg season in SPEI3 values for the three LZs. The recorded SPEI value of the year 1996 for ALOLZ and TCLZ was 2.00. Further, the years of 1993 and 1987 were recorded as the second and third highest wet Belgs in SPEI3 values respectively. The longest persistent wet seasons for SPEI3 values were recorded from 1985 to 1987 and 1995-1997.

Below the spatial drought map in Fig. 4 indicated, in the years of 1984, 1990,1991, 1999, 2009, and 2013 ALOLZ were recorded severe to extremely severe drought Belg seasons with SPEI3 magnitude of $-2.24,-1.51,-2.02$, and $-2.33,-1.84$, and -1.53 respectively. Furthermore as indicated in Table 2 and $100 \%$ of parts of the ALOFLZ were affected from mild to extremely severe drought in the years 1984, 1990,1991, 1994,1999, 2000, 2004, 2007, 2008, 2009, and 2013. However, from 1985 to 1987, 1995-1999 ALOLZ has recorded better precipitation relative to the three livelihood zones. However, from 1992 up to 2016 the TCLZ, and RVLZ were recorded fluctuated dry and wet Belg seasons. In the years of 1988, 1990, 1991, 2001, 2004, 2007, 2009, 2013, and 2014, all parts of (100\%) TCLZ were affected from mild to extremely Belg season drought. All parts of RVLZ were affected by drought in Belg seasons from 1990-1991, 1998-2000, 2004, 2007-2009, and 2013-2014. The rest study years for the study LZs were partially affected by mild to extremely severe drought or free from drought in the Belg season.

The summary of the spatial drought coverage of the study years in the Belg season for the study livelihood zone is presented below in Table 2; Fig. 3 and the trends of area coverage are presented below in Fig. 4. Mohammed's (2018) study indicated that increasing tendency of drought Belg season timescale in the North East Highland of Ethiopia and this study coincided with his study. The trends of drought in the Belg season have steadily increased both temporally and spatially in all LZs in the study years. From 1989 to 2016 the frequencies of drought have increased in Belg within the study years but with a slight difference between the livelihood zones. As seen below in Fig. 4, relatively the two LZs the area coverage of Belg drought has rapidly increased in RVLZ.

\section{Drought condition during the kiremt rain season}

The study area is highly dependent on Kiremt for rain and the majority of agricultural activities and productivities are dependent on the precipitation condition of this season. As stated in Fig. 5 of SPEI3 temporal trends, from 1983 to 2016 in Kiremt mild, moderate, and severe seasonal droughts were recorded. From these seasonal drought years, 7 of them were moderate up to severe seasonal droughts. However, the severity, persistence, and frequencies of the Kiremt drought were seen from1983-1993 in all livelihood zones. The severity, persistence, and frequencies of Kiremt drought were seen in the years 1983, 1984, 1985, 1987, 1989, 1990, 1991, and 1993 in all livelihood zones. The highest extreme severity drought was recorded in SPEI3 in 1984. In this year, SPEI3 recorded from -1.74 in TCLZ to -1.68 in RVLZ. The better wet Kiremt season has occurred in the years 1988, 1994 1998, 2001, 2007, and 2010 in all livelihood zones. Besides, the years of 2012 for RVLZ and 2016 for ALOFLZ and TCLZ were wet Kiremts. The 1998 Kiremt season was the wettest in thirty-four study years for all livelihood zones.

For spatial drought coverage, as seen in Table 3; Fig. 6, from mild to extreme Kiremt drought were occurred on partial or in total study zones. In ALOFLZ, about 87.47, $100,100,100,100,100,92.17,100$, and $62.66 \%$ in the 


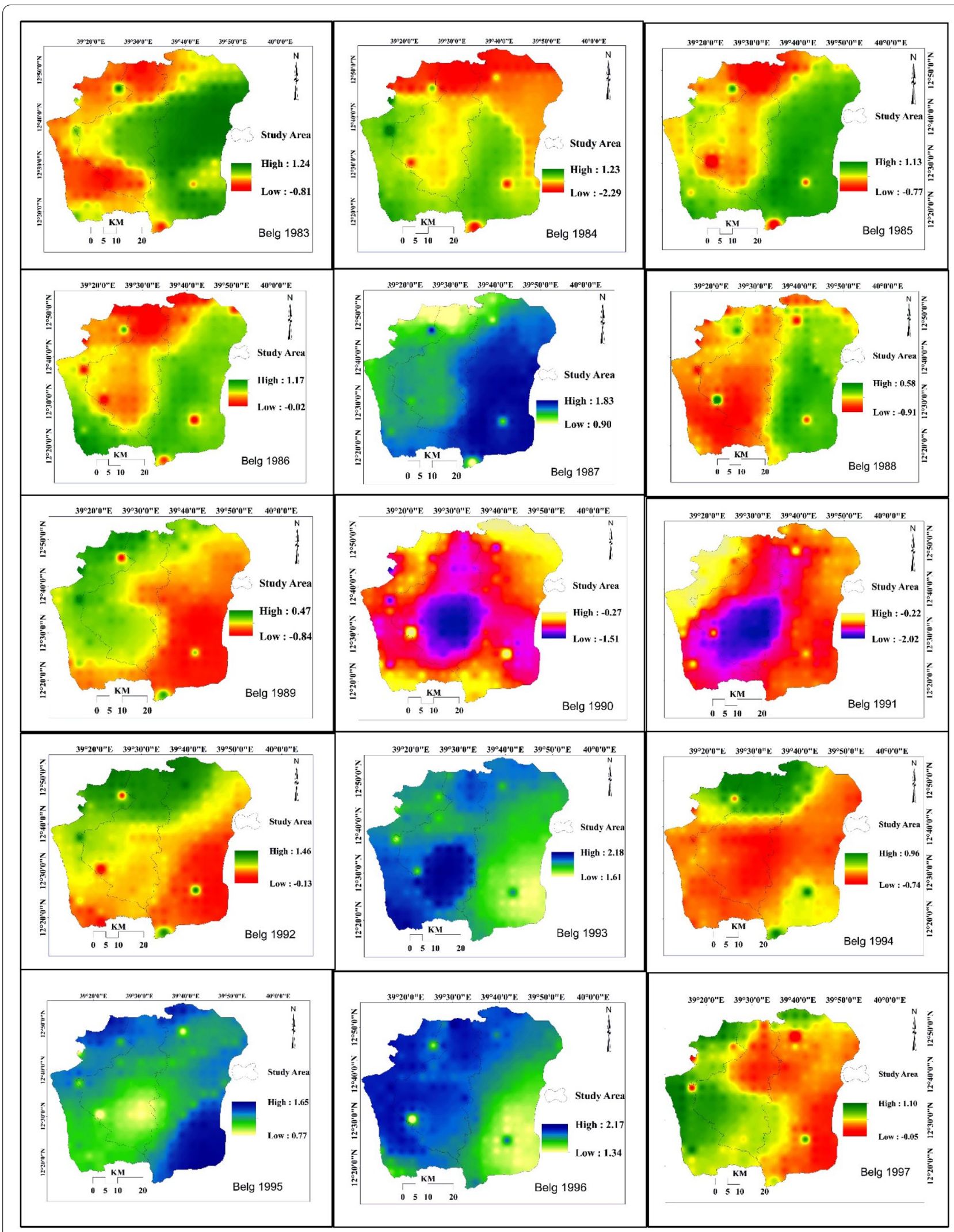

Fig. 3 Map of spatial drought trends in Belg seasons from 1983-2016 


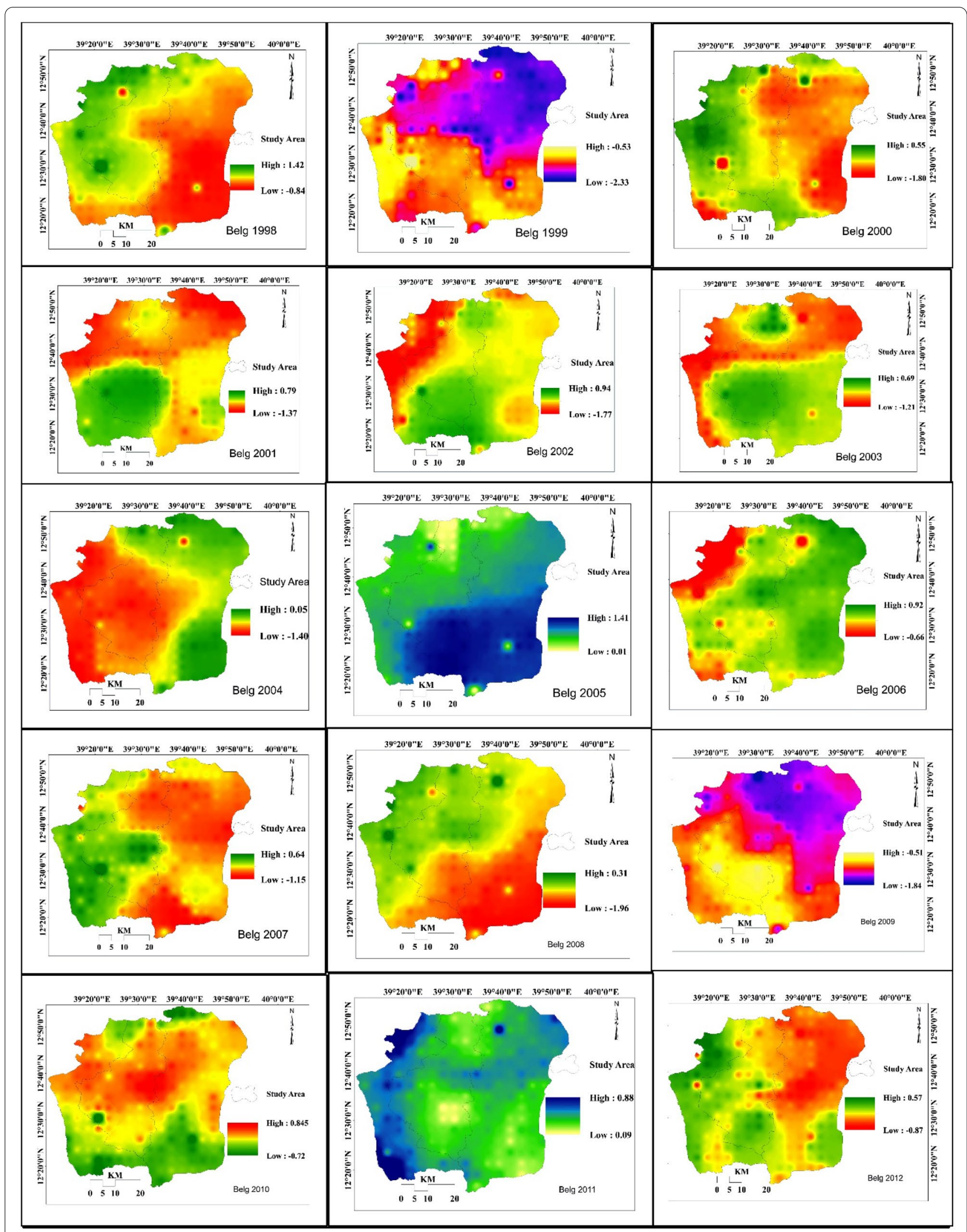

Fig. 3 continued 


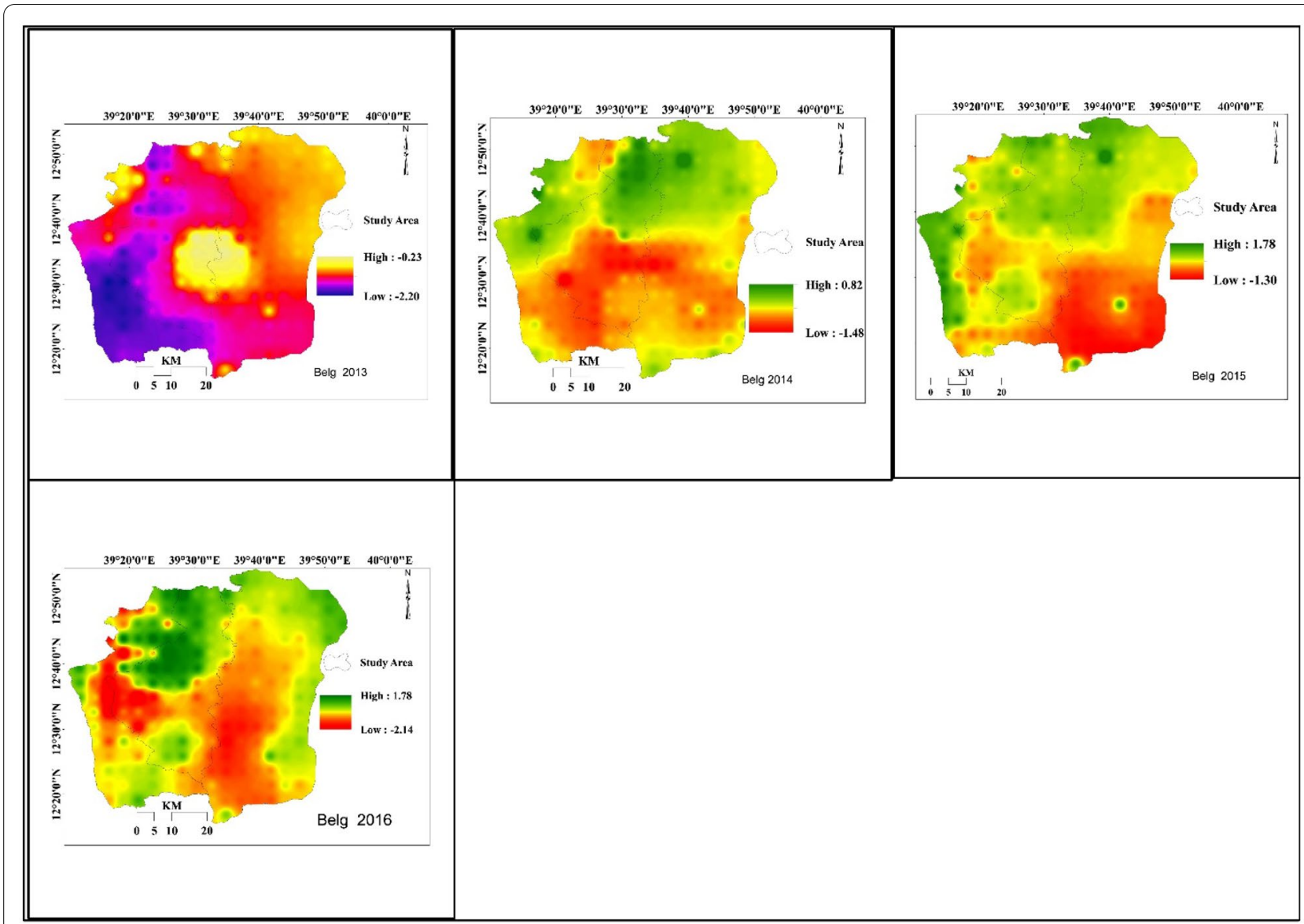

Fig. 3 continued

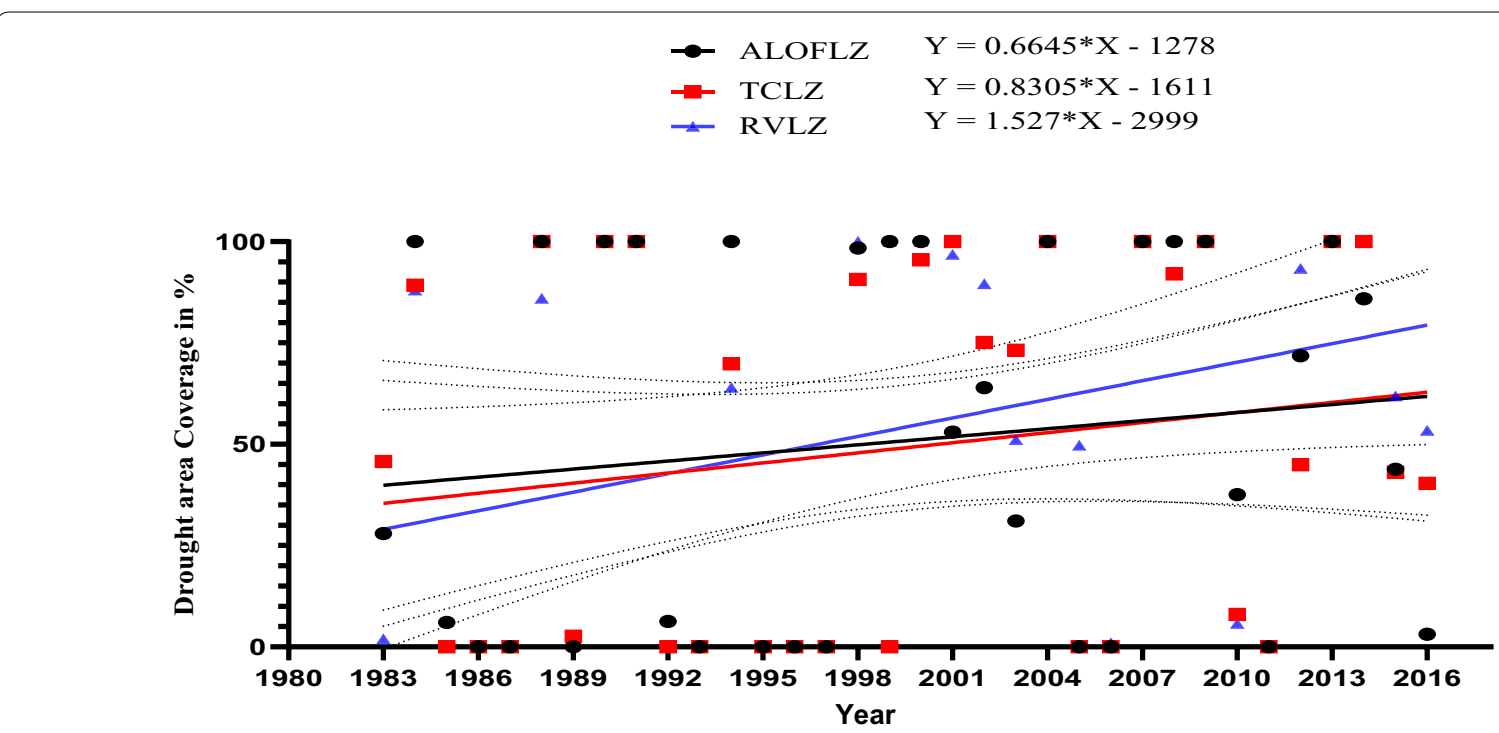

Belg Drought Area Coverage Trends

Fig. 4 The spatial drought trends in \% of area coverage from 1983 to 2016 using GraphPad Prism in Belg season. 

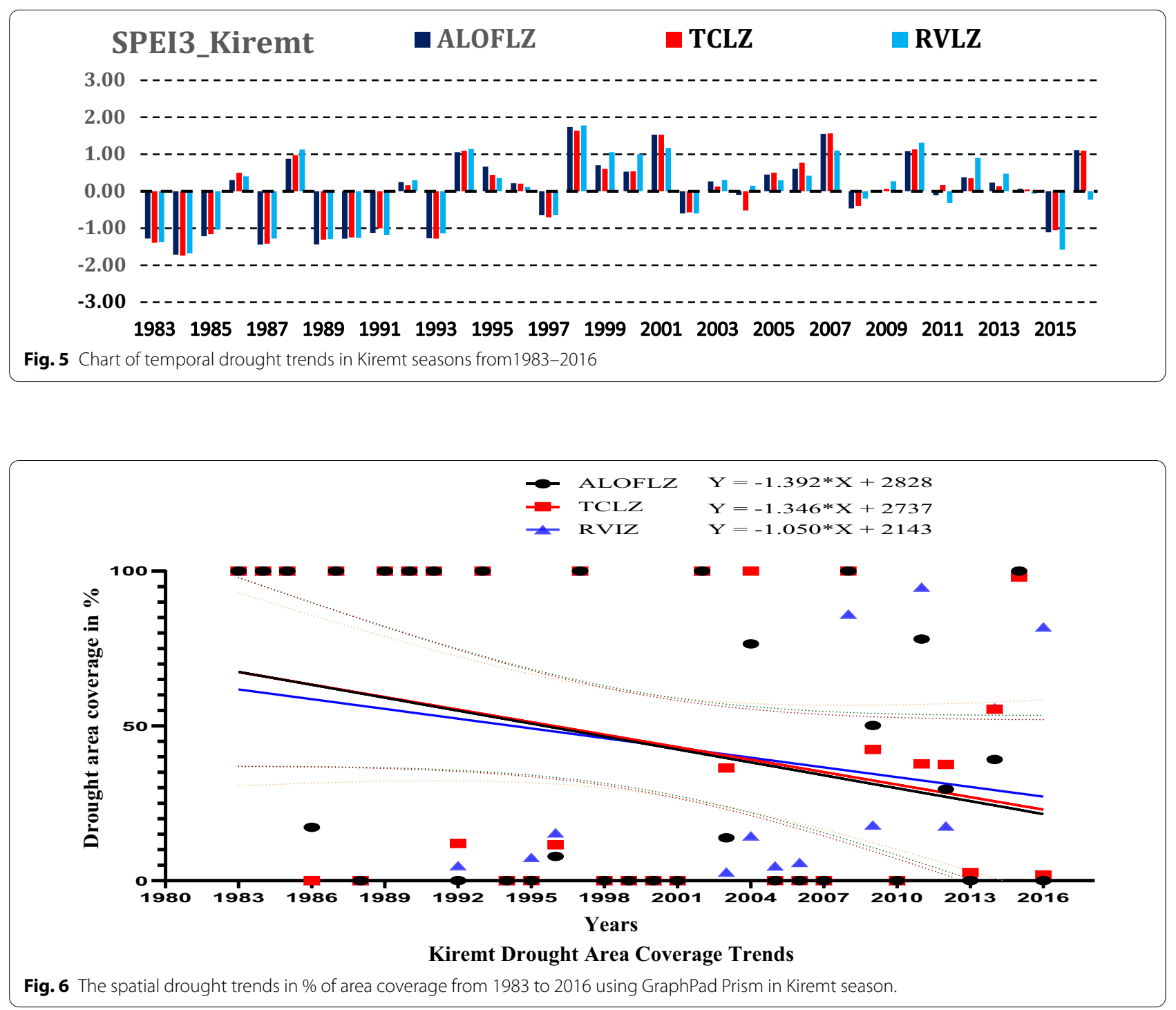

years of 1983, 1984, 1985, 1987, 1990, 1991, 1993 and 20,015 were affected from moderate to extreme Kiremt drought respectively. Besides moderate to extreme Kiremt drought in TCLZ were 98.14, 100, 100, 97.38, 100, $100,43.96,100,1.58,9.99$ and 62.66 of the area affected in the years of 1983, 1984, 1985, 1987, 1989, 1990, 1991, 1993, 2002, 2004, and 20,015 respectively. Moderate to extreme Kiremt drought in RVLZ were covered the area of 96.36, 99, 79.47, 97.19, 98.13, 100, 100, 97.56, 2.79, 85.16 and $62.66 \%$ in the years of 1983, 1984, 1985, 1987, 1998, 1990, 1991, 1993, 2002, 2008, and 20,015 respectively. As seen in Fig. 6, the spatial drought trends in area coverage slightly decreased in all LZs.

Even if the drought frequencies were reduced from 2001 to 2016, the 7 wet Kiremt seasons were recorded below 0.5 SPEI values which were mild wet. This precipitation value was too low for agricultural practices. A plant's demand for water is dependent on prevailing meteorological conditions and vulnerable to dry weather conditions. These small precipitation sources and frequently happened mild spatiotemporal metrological drought in the study LZs, the agricultural scoter has been badly affected. Besides, the Kiremt drought season becoming locally fragmented even at village levels. Little is heard, about the study area except when large-scale drought occurs at regional or nationwide scales. This study coincides with (Gidey 2012) study that stated, an isolated drought is a particularly dangerous drought for the affected people. Furthermore, drought is often elapsed once it ends, and consequently, the government will again be ill-informed when the next large scale drought occurs. For all study years and study 


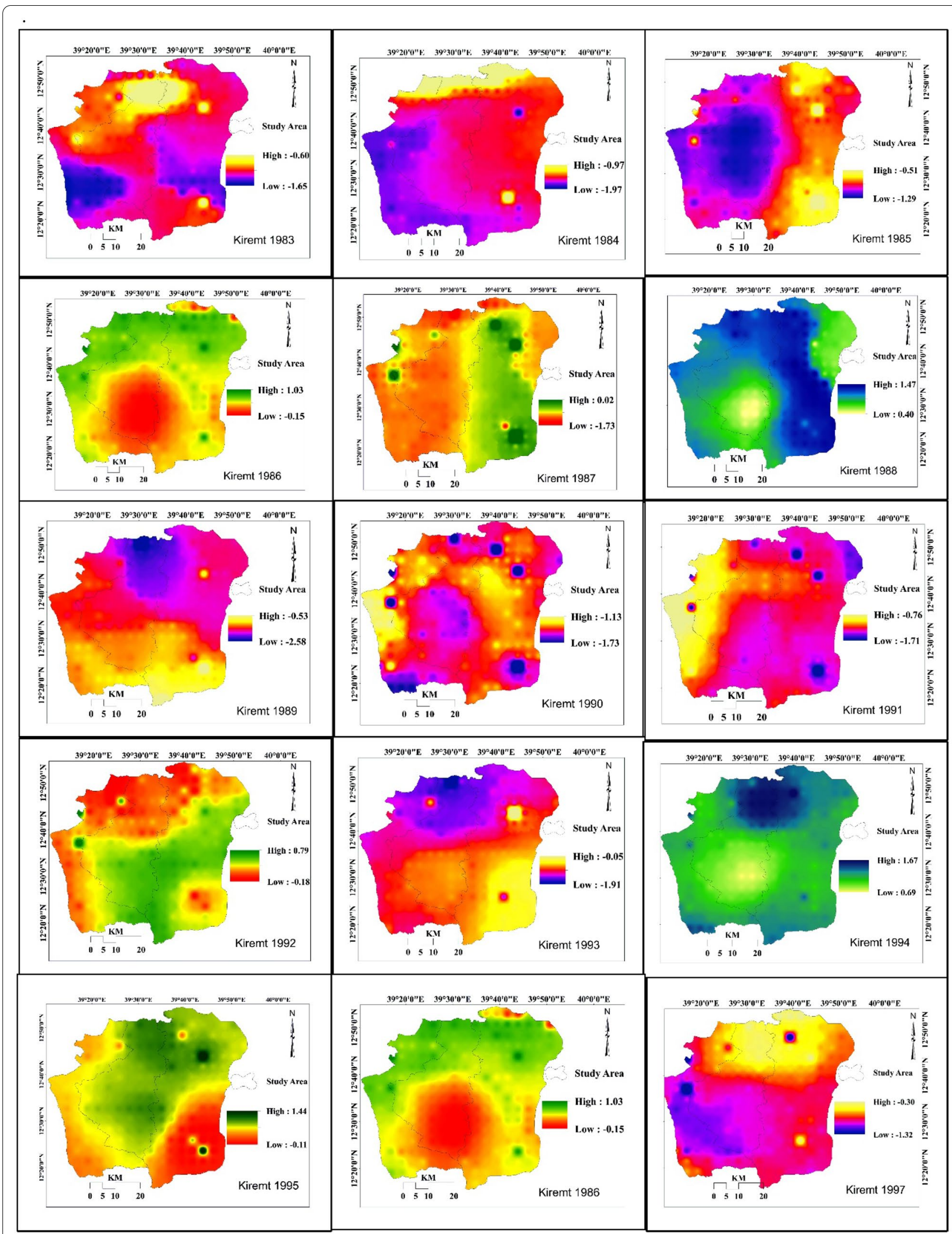

Fig. 7 SPEI3 spatial trends of drought and wet maps of Kiremt seasons 


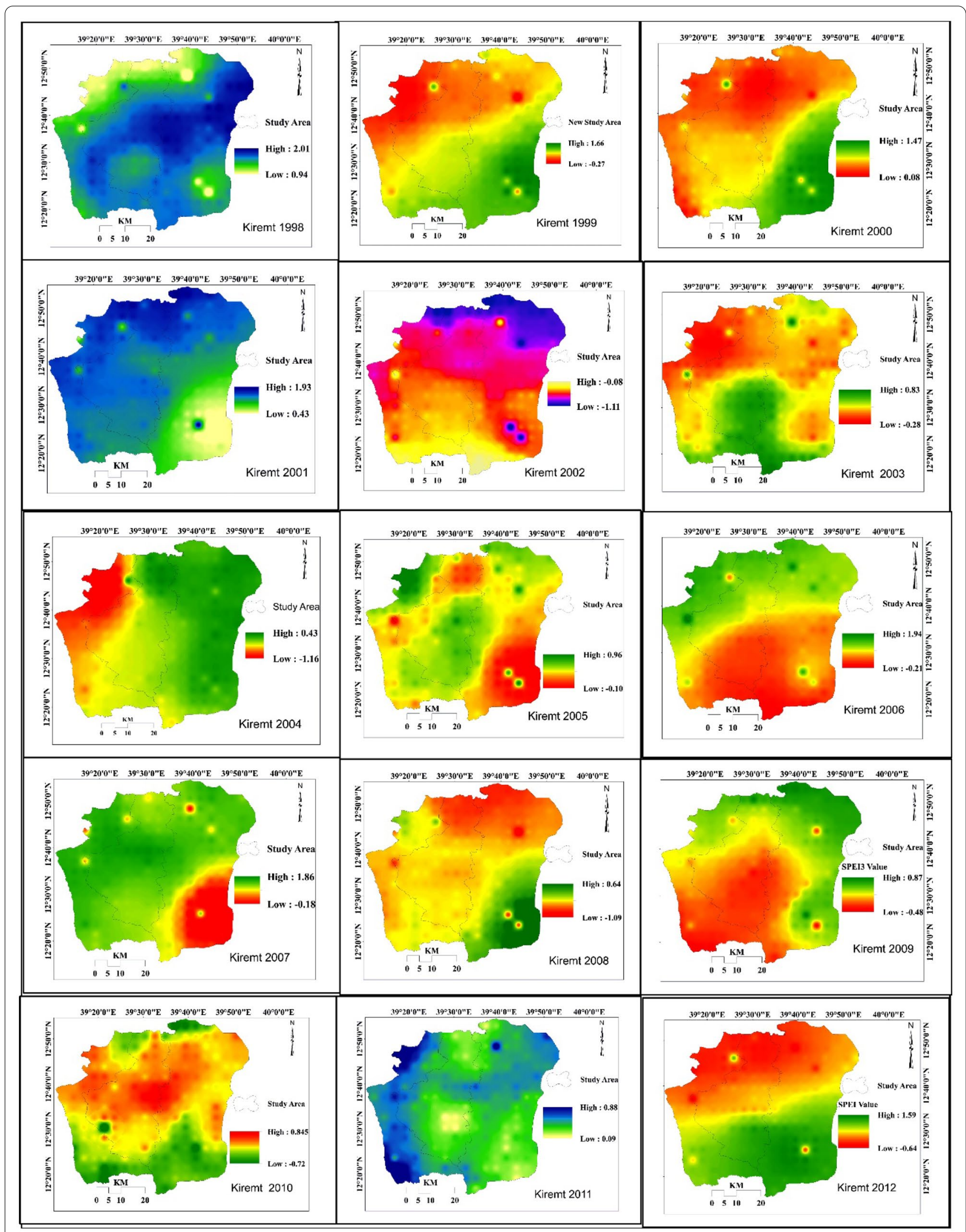

Fig. 7 continued 


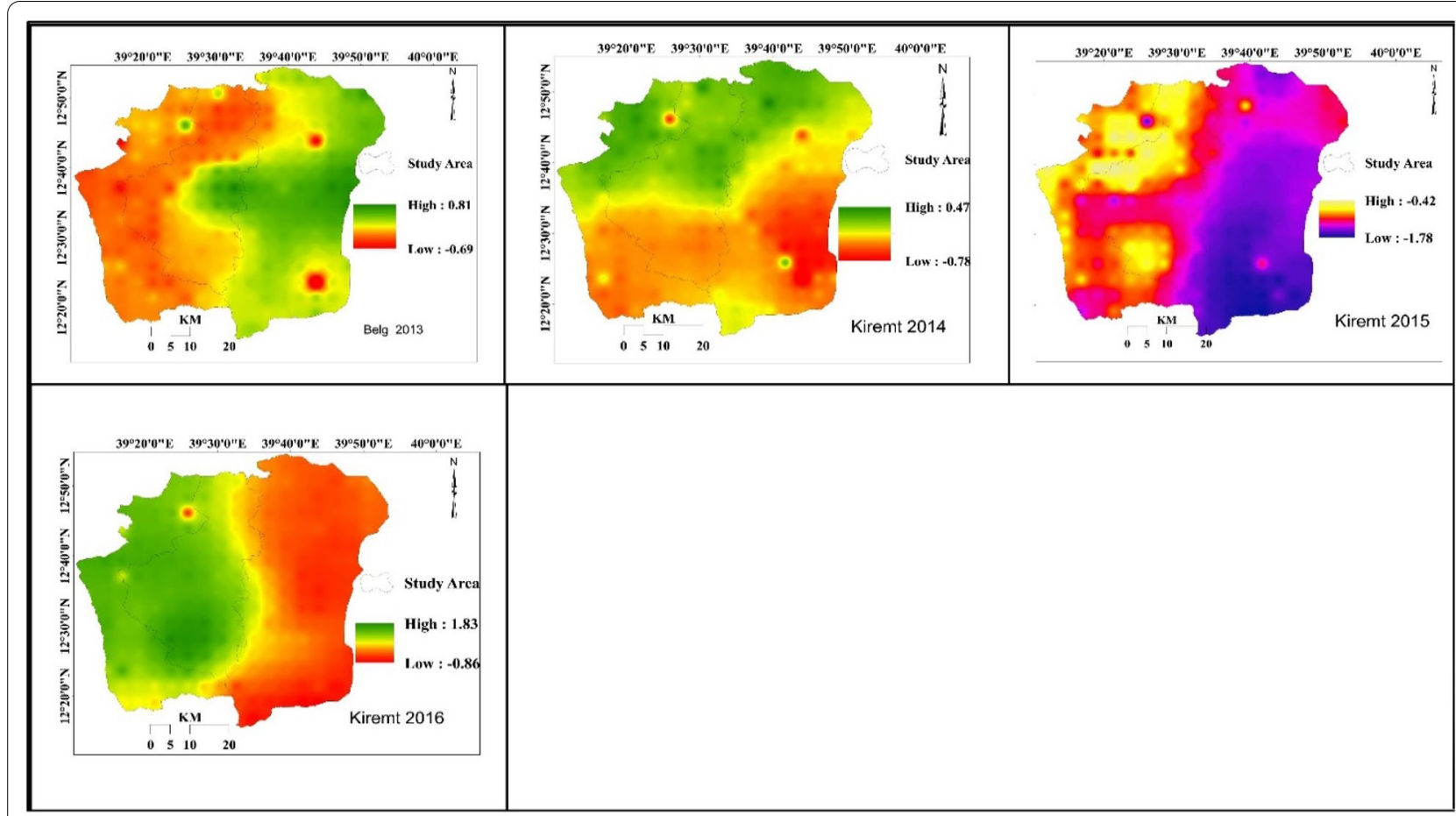

Fig. 7 continued

livelihood zones, all spatial drought magnitudes from mild to extreme Kiremt drought were presented below in Table 3. For Kiremt drought and wet seasonal trends, for the study area and the study years, the following SPEI3 Fig. 5 temporal charts and spatial SPEI maps in Fig. 7 were presented.

\section{Drought condition both during the Belg and Kiremt rainy seasons}

This part focuses on the average combined rainy seasons of the study area. Using SPEI6, the drier and wettest years for the 6 months from March-August were analyzed. From 1983 to 1991, there were 2 wet and 7 consecutive drought years in all livelihood zones in SPEI6 for the study months. However, from 1992 to 2007, there were 2 droughts and 10 wet recorded years for 6 months. Besides in 2010 and 2012 for all livelihood zone, and 2016 for ALOFLZ and TCLZ were recorded as wet years. Generally, from 1983 to 2016, 15 droughts were recorded for the combined rainy season in all livelihood zones; with 2 additional drought seasons for RVLZ. From 1983 to 1991 long durations and the high severities of drought were occurred in all livelihood zones in SPEI6 records. The lowest recorded SPEI6 value in the year 1984 was ranged from -1.90 in ALOFLZ to - 1.77 in RVLZ. For further information to see temporal and spatial drought trends using SPEI6 records for each year for the combined rainy season and all livelihood zones are presented below in Figs. 8 and 9 respectively. As seen below in Fig. 9, the area coverage of the combined rainy season slightly decreasing in both ALOFLZ and TCLZ, but increasing in RVLZ.

\section{Discussion \\ Drought condition during the Belg rain season}

The trends of drought in the Belg season has steadily increased both temporally and spatially in all LZs. From 1989 to 2016, the frequencies of drought have increased in Belg with a slight difference between the livelihood zones. From 1983 to 2016 in Belg 18, mild, moderate, and severe temporal droughts were recorded. The frequencies of seasonal drought for Belg had increased since 1998 in all livelihood zones. The long and persisted drought years of the Belg season were occurred for seven years from 1998 to 2004 and followed by five drought seasons from 2012 to 2016. The current study agreed with Haile and Tang (2019) findings that stated drought tends to be more frequent and more severe in the boreal spring (Belg Season) in East Africa. Mohammed (2018) study indicated that increasing tendency of drought Belg season in the North East Highland of Ethiopia. This study coincided with his findings in all study LZs. From 1983 to 1999 , there were high severity and short frequencies of temporal Belg drought. Within the past thirty-four years (1983-2016), 1999 was recorded as the severe temporal 


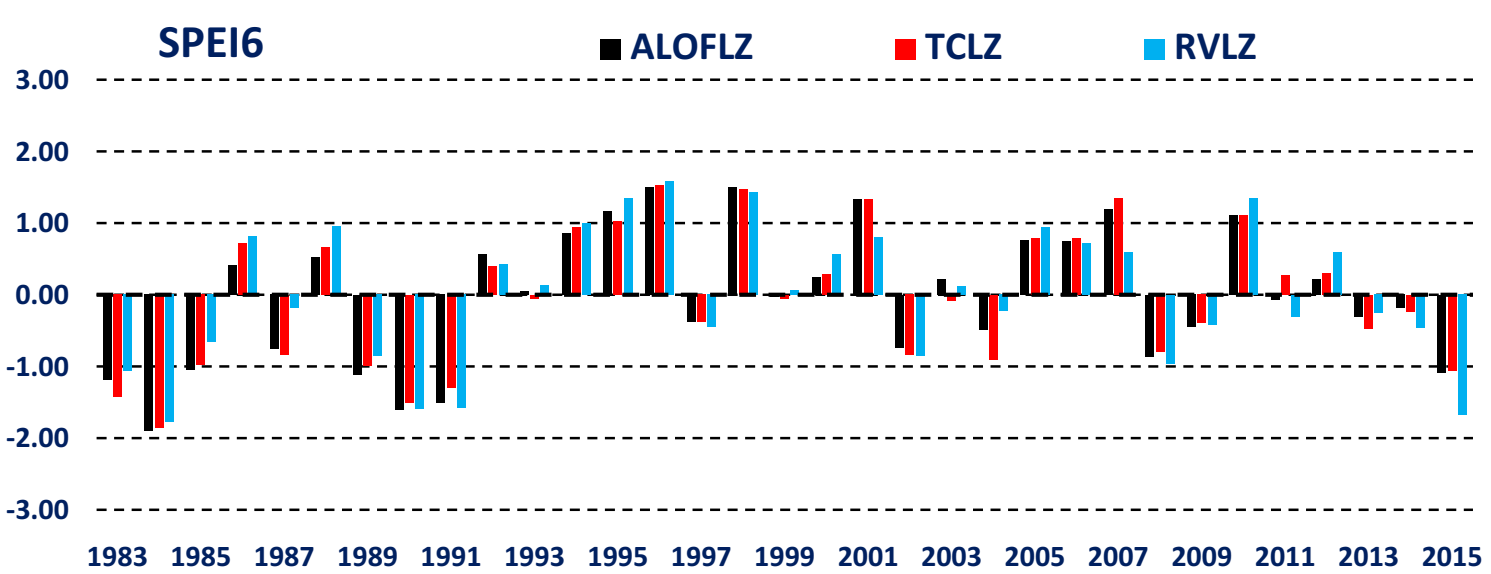

Fig. 8 Chart of temporal drought trends in combined rainy season's from1983-2016

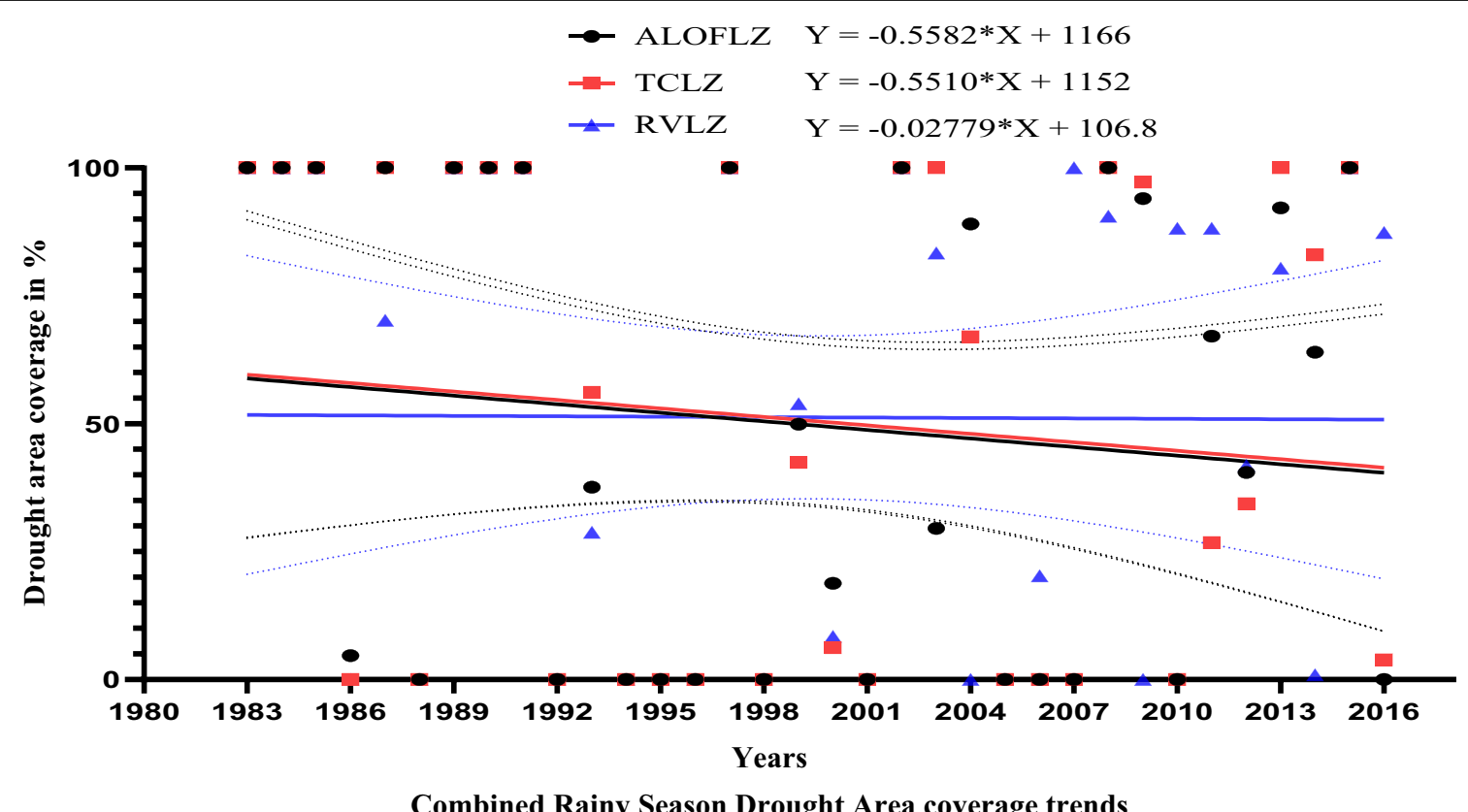

Fig. 9 Spatial drought trends in \% of area coverage from 1983-2016 using GraphPad Prism in combined rainy seasons

Belg drought in SPEI3 in all livelihood zones. The SPEI 3 magnitude at LZ levels were ranged from -1.71 in TCLZ to -1.88 SPEI values in RVLZ.

For spatial drought coverage, from mild to extreme Belg drought were occurred on partial or in all study LZs. At gird point levels, in ALOLZ, severe to extreme spatial Belg drought were recorded. Further, from mild to extremely severe droughts were affected by $100 \%$ of the ALOFLZ in the years 1984, 1990, 1991, 1994, 1999, 2000, 2004, 2007, 2008, 2009, and 2013. However, from 1985 to 1987,1995 to1999 ALOLZ has recorded better precipitation relative to the three livelihood zones. From 1992 up to 2016 the TCLZ, and RVLZ were recorded fluctuated dry and wet Belg seasons. All parts of (100\%) TCLZ were affected from mild to extremely Belg season drought in the years 1988, 1990, 1991, 2001, 2004, 2007, 2009, 2013, and 2014. The whole parts of RVLZ were affected by drought in Belg seasons from19901991, 1998-2000, 2004, 2007-2009, and 2013-2014. The rest study years for the study LZs were partially affected from mild to severe drought or free from seasonal Belg drought. 


\section{Drought condition during the Kiremt rain season}

The study area is highly dependent on Kiremt for rain, and the majority of agricultural activities and productivities are dependent on the precipitation condition of this season. However, from 1983 to 2016, 12 temporal droughts were recorded in Kiremt. From these seasonal drought years, 7 of them were moderate up to severe seasonal droughts. From1983 to 1993, Kiremt drought severity, persistence, and frequencies have occurred in all livelihood zones. The most severe drought recorded in the year 1984 in all LZs. In this year, SPEI 3 values were recorded from -1.74 in TCLZ to -1.68 in RVLZ. From 1989 to 2016 the frequencies of drought have increased in Belg and decreased in Kiremt. The frequencies and severity of drought were a slight difference between the livelihood zones. Yearly there were Kiremt or Belg or both season drought in local or in livelihood zone levels. In the Kiremt season, extreme to severe drought becoming decreasing, but moderate to mild drought frequencies and persistence were increasing in all livelihood zone. Drought occurrences in this season, becoming locally fragmented even at village levels.

Mohammed (2018) study indicated that increasing tendency of drought Belg season but a reducing tendency in Kiremt and the annual timescale in the North East Highland of Ethiopia. This study partially coincided with the study's' of Mohammed (2018). Even if the drought frequencies have reduced from 2001 to 2016, 7 of wet Kiremt seasons recorded below 0.5 SPEI values. This 0.5 SPEI value was mild wet and too low for agricultural practices and ecosystem stability. This study also agreed with Kenawy et al. (2016) findings on changes in the frequencies and severity of hydrological droughts over Ethiopia, which reveal a statically significant decrease in the severity of droughts (extreme and severe drought) compared to the moderate drought over the 54 years (1960-2013). This study also coincides with Zeleke (2017) findings on drought trends and periodicity over all Ethiopia from 1979 to 2014. The severity and frequencies of drought in this study were higher from 1983 to 1991, better 1993 to 1998 , and returned mildly to moderate drought from 2000 to 2016. The current study coincides with Gidey et al. (2018a, b, c) on the increasing frequencies and persistence of drought. Their findings stated that drought frequencies, durations, and severity are higher in the lowland area than in the mid and highlands during the last 15 years. However, since 2000 drought severity in Kiremt was reduced in the study livelihood zones except for 2015. Further, Gidey et al. (2018a, b, c) findings show that 2001, 2003, 2003, 2006, 2007, and 2010 years were free from incidences of agricultural drought in their study area but, theses years were not drought-free in the current study area, which is parts of their study area.
For spatial drought coverage, from mild to extreme Kiremt drought were occurred on partial or in all study LZs. From 1984 to 1998 in Kiremt and the combined rainy season droughts have been relatively severe in ALOFLZ and TCLZ than in RVLZs. However, from 1992 to 2016, the ALOFLZ and TCLZ were relatively recorded moderately wettest Kiremt than RVLZs. Mild to severity short Kiremt drought frequencies frequently happened from 1997 to 2016 in TCLZ and RVLZ than ALOLZ.

\section{Drought condition during the combined rainy seasons}

This part focuses on the average combined rainy seasons of the study area. Using SPEI6 drier and wettest years for the six months from March-August were analyzed. The moisture amount of these months implies the evapotranspiration budge and its process. There are long and short growing season crops that are sensitive to the two wet seasons of rain conditions. During one of the rainy seasons failed, the long and short seasonal growing crop failure has happened in the area. In most of the study years, there have been Belg or Kiremt or both drought seasons in the study areas. From 1983 to 1991, there were 2 wet seasons and 7 consecutive drought years in all livelihood zones in SPEI6 for the study months. However, from 1992 to 2007, there were 2 droughts and 10 wet recorded years for six months. The years of 2010 and 2012 for all LZs, and 2016 for ALOFLZ and TCLZ were recorded as wet years. Generally, from 1983 to 2016, 15 droughts were recorded for the combined rainy season in all livelihood zones; with 2 additional drought seasons for RVLZ. All livelihood zones had severity drought from SPEI6 records in the years 1983, 1984, 1989, 1990, 1991, and 2015 for RVLZ. The lowest recorded SPEI6 value in the year 1984 was ranged from - 1.90 in ALOFLZ to - 1.77 in RVLZ.

Tefera et al. (2019) studied drought occurrence patterns in the Tigray region in northern Ethiopia. Their result indicated the most districts southern (which includes the study LZs) and eastern zones experienced intense droughts than the rest of their study area. Their findings revealed an increase in drought occurrences and spatially variability drought duration, severity, intensity, and frequencies in the region. Spatial drought trend variability trend also reported by Nabaei et al. (2019) in Iran. This study agreed with Tefera et al. (2019) finding, except for the frequencies of drought severity occurrences. Mild to moderate drought decreasing in spatial and temporal trends in the study years. This study more coincides with Ghebrezgabher et al. (2016) and Zeleke (2017) findings on the severity of drought occurrences decreeing, but mild to moderate drought occurrences were escalating temporally and spatially in the study area during the study period. 


\section{Conclusions}

This study analyzed the trends of spatiotemporal seasonal drought frequencies, durations, and severity in LZ levels. Studying drought with long recorded meteorological data from a large number and uniformly distributed meteorological grids in small scale livelihood zones has great implications to identify the real trends of Spatiotemporal meteorological drought. This study enabled the researchers to investigate the drought frequencies, severity, and durations in small scale areas. The short and medium time scales (3 and 6 months) have positive implications to see the spatiotemporal drought frequencies, magnitudes, and severities. Studding drought in small scale livelihood zones has advantages to find out natural and human-induced drought susceptible areas.

The Belg and Kiremt temporal drought had an inverse relationship with drought histories in the study area within-study years. If Kiremt gets good rain in some years, the Belg did not get, and there were versus. From 1989 to 2016 the frequencies of drought have increased in Belg and decreased in Kiremt within the study years. However, the frequencies and severity of drought were slight differences between the livelihood zones. Seasonal drought Kiremt becoming locally fragmented even at village levels. This problem needs special considerations on the current moisture harvesting system and afforestation practices to reduce human-induced drought impacts. As this study uncovered, long before 25 years, drought causalities were tremendous in the lives of humans and livestock in the study area. As the frequencies and persistence of mild drought have increased, the intensity and precipitation amount are too small to cultivate crops and forage growth. This Consequence, the recent drought incidents of the study area have more fatalities to the livestock than to human suffering. Human Bing may search other alternative income sources like power sale, remittance income sources, relief supports, and firewood sales to sustain the household.

Spatially the authors find that there were seasonally recurring droughts that vary in severity, frequencies, and durations within and between the livelihood zones. Drought frequency and persistence have been increasing in RVLZ and followed by TCLZs. In most of the study years, there have been seasonally or yearly human or climate-induced droughts occurrences in grid point levels or livelihood zone scale in RVLZ and TCLZ. In the last thirteen years (2003-2016), the RVLZ has suffered immensely due to persistent drought incidents. However, in the same years, the central parts of ALOFLZ have been less vulnerable to drought than others.

This study will support to improve the existing drought monitoring system and to build resilience to drought at the household level. The finding also will have a significant contribution to early warning systems, particularly at district levels. Ended, it needs to consider solutions for short and long drought impacts. The agricultural sector should consider the long-cycle crop growth patterns to reduce crop failures and forage problems.

On the ground, further study needs to see the causes and impacts of drought at livelihood zone levels. The Belg and Kiremt rainfall onsets, durations, terminations, and variavilities trends are needs in-depth investigations to put appropriate agricultural activities. If local community perceptions on drought occurrences, frequencies, and impacts, their adopting and adaptation mechanism are studied well, it will help to put appropriate measurements and interventions to reduce crop failures and forage problems in local levels too.

\section{Acknowledgements}

The authors are grateful to Addis Ababa and Aksum Universities for their financial supports. The authors also wish to thank the Ethiopian Meteorology Agency for providing the meteorological data used in this study.

\section{Authors' contributions}

The correspondent author initiates the research idea, reviews relevant literature, design the methods, field data collection, data cleaning, analysis, interpretation, and prepare draft manuscripts for publication. Coauthors evaluate the research idea, supervise the whole research activities, and develop the manuscript. All authors read and approved the final manuscript.

Funding

This research partially got fund by Addis Ababa University and Aksum University for data collection and processing only.

\section{Availability of data and material}

The data was present with an additional supporting file.

\section{Ethics approval and consent to participate}

This research paper is part of our project entitled'Synergetic Impact of Drought and Land Use Land Cover Dynamics on Livelihood of the Local Communities in Northern Western Escarpments of Ethiopian Rift Valley.'Therefore, all authors approve to publish the findings, and there is no ethical conflict.

Consent for publication

All authors read the manuscript and agreed to publication.

Competing interests

The authors declare that they have no competing interests.

\section{Author details}

${ }^{1}$ Center for Environmental and Development Studies, College of Development Study, Addis Ababa-University, P. O. Box: 1176, Addis Ababa, Ethiopia. ${ }^{2}$ Department of Soil Resources and Watershed Management, College of Agriculture, Aksum University, P.O.Box:314, Axum, Ethiopia. ${ }^{3}$ Department of Land Resources Management and Environmental Protection (LaRMEP), College of Dryland Agriculture and Natural Resources, Mekelle University, P.O. Box: 231, Mekelle, Ethiopia.

Received: 28 November 2020 Accepted: 23 January 2021

Published online: 12 February 2021

\section{References}

Abbasi A, Khalili K, Behmanesh J, Shirzad A (2019) Drought monitoring and prediction using SPEI Index and Gene Expression Programming Model in the West of Urmia Lake. Theoret Appl Climatol 138(1-2):553-567 
Abrha MG, Simhadri S (2015) Local Climate Trends and Farmers 'Perceptions in Southern Tigray, Northern Ethiopia. J Environ Sci 11(4):262-277

Andargie G (2014) Military Rule Responses to the Ethiopian Agony: Famine of 1984-1985. International Journal of Humanities Social Sciences Education 7(8):183-192

Annys S, Demissie B, Zenebe A, Miro A (2016) Land cover changes as impacted by Spatio-Temporal rainfall variability along the Ethiopian Rift Valley Escarpment. Reg Environ Change 17(8):451-463

Bae S, Lee S, Yoo S (2018) Analysis of Drought intensity and trends using the modified SPEl in South Korea from 1981 to 2010. Water 10(3):327

Beguería S, Vicente-Serrano SM, Reigb F, Latorrea B (2014) Standardized precipitation evapotranspiration index (SPEI) revisited : parameter fitting , evapotranspiration models, tools, datasets and drought monitoring. Int J Climatol 3023:3001-3023. https://doi.org/10.1002/joc.3887

Beharry SL, Gabriels D, Lobo D, Clarke RM (2019) A 35-year meteorological Drought analysis in the Caribbean Region: case study of the small Island State of Trinidad and Tobago. SN Appl Sci 1(10):1-16

Biru D, Amanuel M, Dibaba (2018) Assessment on the Operationalization of Drr System at Local Level. Asist Mission Report September 2018, 35. International Cooperation and Development

Chen S, Zhang L, Zhang Y, Guo M, Liu X (2020) Evaluation of Tropical Rainfall Measuring Mission (TRMM) satellite precipitation products for drought monitoring over the middle and lower reaches of the Yangtze River Basin, China. J Geog Sci 30(1):53-67

Dai A (2011) Drought under Global Warming. WIREs Clim Change 2(1):45-66

Diaz V, Corzo GA, Lanen HAJ, Van, Solomatine D, Varouchakis EA (2020) An approach to characterise spatio-temporal Drought dynamics. Adv Water Res 137(7):103512

Drechsler M, Soer W (2016) Early warning, early action: the use of predictive tools in Drought response through Ethiopia's Productive Safety Net Programme. Policy Research Working Paper; No. 7716. World Bank, Washington, DC. @ World Bank

EM-DAT (2014) The figures were summarized from EM-DAT | The international disasters database

EM-DAT (2017) https://www.emdat.be/publications?page =1

FEWS NET (2018) Ethiopia Livelihoods Zone Map.https://fews.net/east-africa/ ethiopia/livelihood-zonemap/january-2018. Accessed 10 Jun 2020

Ghebrezgabher MG, Yang T, Yang X (2016) Long-term trend of climate change and Drought assessment in the horn of Africa. Adv Meteorol 2016(10):12

Gebru GW, Beyene F (2012) Rural household livelihood strategies in DroughtProne areas: the case of Gulomekeda District, Eastern Zone of Tigray National Regional State, Ethiopia. J Dev Agric Econ 4(6):158-168

Ghozat A, Sharafati A, Hosseini SA (2020) Long-term spatiotemporal evaluation of CHIRPS satellite precipitation product over different climatic regions of Iran. Theor Appl Climatol 143:211-225

Gidey E, Dikinya O, Sebego R, Segosebe E, Zenebe A (2018a) Analysis of the long - term agricultural Drought Onset, cessation, duration, frequency, severity and spatial extent using Vegetation Health Index (VHI) in Raya and its environs, Northern Ethiopia. Environ Syst Res. https://doi. org/10.1186/S40068-018-0115-Z

Gidey E, Dikinya O, Sebego R, Segosebe E, Zenebe A (2018b) Modeling the Spatio-Temporal Meteorological Drought characteristics using the Standardized Precipitation Index (SPI) in Raya and its environment. Earth Syst Environ 2(2):2006

Gidey E, Dikinya O, Sebego R, Segosebe E, Zenebe A (2018c) Predictions of future meteorological drought hazard ( 2070$)$ under the representative concentration path ( RCP ) 4.5 climate change scenarios in Raya, Northern Ethiopia. Mod Earth Syst Environ. https://doi.org/10.1007/s4080 8-018-0453-x

Gidey E, Dikinya O, Sebego R, Segosebe E, Zenebe A (2018d) Using Drought indices to model the statistical relationships between meteorological and agricultural Drought in Raya and its environs. Earth Syst Environ. https:// doi.org/10.1007/S41748-018-0055-9

Gidey TG (2012) Food Security Policy: Does It Work? Does It Help? Research output: Ph.D. Thesis. The University of Twente, Faculty of Geo-Information Science and Earth Observation (ITC)

Haile GG, Tang Q (2019) Earth-Science Reviews Droughts in East Africa: Causes, impacts, and resilience. Earth Sci Rev 193:146-161
He B, Lü A, Wu J, Zhao L, Liu M (2011) Drought hazard assessment and spatial characteristics analysis in China. J Geog Sci 21 (2):235-249

Hurni H, Zeleke G (2018) Soil and Water Conservation in Ethiopia (Issue April)

Kenawy AMEL, Mccabe MF, Robaa SM (2016) Changes in the Frequency and Severity of Hydrological Droughts over Ethiopia from 1960 to 2013. Cuadernos De Investigación Geográfica 42(1):145-166

Kiros FG (1991) Economic consequences of Drought, crop failure, and famine in Ethiopia, 1973-1986. Royal Swedish Acad Sci 20(5):183-185

Lu H, Mo X, Liu S (2015) Intercomparison of three indices for addressing Drought variability in North China Plain during 1962-2012. Proceedings of the International Association of Hydrological Sciences 366(4): 141-142

Mckee TB, Doesken NJ, Kleist J (1993) The relationship of drought frequency and duration to time scales. In: Proceedings of the 8th conference on applied climatology. American mete-orological society, 17(January), 179-183

Masih I, Maskey S, Trambauer P (2014) A Review of Droughts on the African Continent: a geospatial and long-term perspective. Hydrol Earth Syst Sci 18(9):3635-3649

Mavromatis T (2012) Changes in exceptional hydrological and meteorological weekly event frequencies in Greece. Clim Change 110(1):249-267

Mohammed Y (2018) Meteorological Drought assessment in North East Highlands of Ethiopia. Int J Clim Change Strat Manag 10(1):142-160

Nabaei S, Sharafati A, Mundher Z, Shahid S (2019) Agricultural and Forest Meteorology Copula based assessment of meteorological drought characteristics: regional investigation of Iran. Agric For Meteorol 276-277(June):107611

Sadat T, Hosseini M, Hosseini SA, Ghermezcheshmeh B, Sharafati A (2020) Drought hazard depending on elevation and precipitation in Lorestan, Iran. Theor Appl Climatol 142:1369-1377

Sharafati A, Nabaei S, Shahid S (2019) Spatial assessment of meteorological drought features over different climate regions in Iran. Int I Climatol 2019:1-21

Shi B, Zhu X, Hu Y, Yang Y (2017) Drought characteristics of Henan province in 1961-2013 based on Standardized Precipitation Evapotranspiration Index. J Geog Sci 27(3):311-325

Tefera A, Ayoade J, Bello N (2019) Drought Occurrence Pattern in Tigray Region, Northern Ethiopia. J Appl Sci Environ Manage 23(July):1341-1348

Tefera AS, Bello JOANJ (2019) Comparative Analyses of SPI and SPEl as Drought Assessment Tools in Tigray Region, Northern Ethiopia. Sn Applied Sciences 1(10): 1-14

The Livelihoods Integration Unit (2010) An Atlas of Ethiopian Livelihoods

Tian L (2019) Spatial and temporal patterns of Drought in Oklahoma. Int J Climatol 39(3):3365-3378

Vicente-Serrano SM, Beguería S, Lorenzo-Lacruz J, Camarero JJ, López-Moreno Jl, Azorin-Molina C, Revuelto J, Morán-Tejeda E, Sanchez-Lorenzo A (2012) Performance of Drought indices for ecological, agricultural, and hydrological applications. Earth Interactions 16(10):1-27

Webb P, Braum J (1990) Drought and food Shortagesin Ethiopia: a preliminary review of effects and policy implications. International Food Policy Research Institute, March, p 176

Yacoub E, Tayfur G (2020) Spatial and temporal of variation of meteorological Drought and precipitation trend analysis over whole Mauritania. J Afr Earth Sci 163(1):103761

Zarei AR (2019) Analysis of changes trend in spatial and temporal pattern of Drought over South of Iran using Standardized Precipitation Index (SPEI). SN Appl Sci 1(5):1-14

Zeleke TT (2017) Trend and periodicity of Drought over Ethiopia. Int J Climatol $37(13): 4733-4748$

Zhang J, Shen Y (2019) Spatio-temporal variations in extreme drought in China during 1961-2015. J Geog Sci 29(1):67-83

\section{Publisher's note}

Springer Nature remains neutral with regard to jurisdictional claims in published maps and institutional affiliations. 